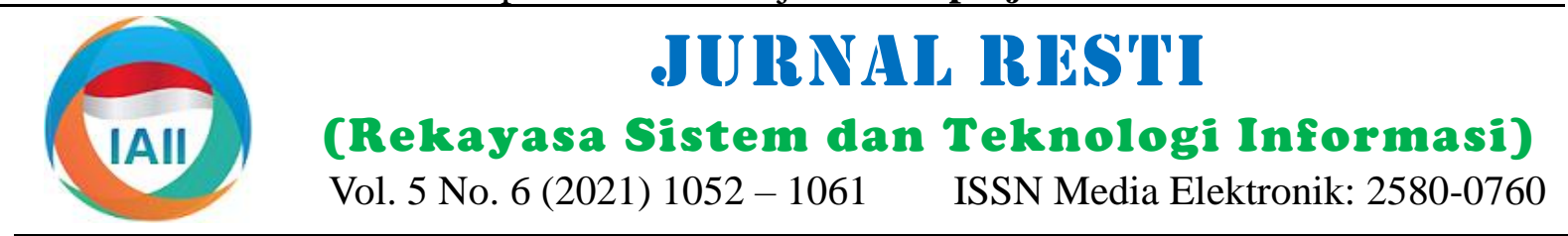

\title{
Pengembangan Antarmuka Portal Universitas untuk Meningkatkan Pengalaman Pengguna
}

\author{
Asmuliardi Muluk ${ }^{1}$, Ikhwan Arief ${ }^{2 *}$, Ahmad Syafruddin Indrapriyatna $^{3}$, Mahira Falevy ${ }^{4}$ \\ ${ }^{1234}$ Teknik Industri, Fakultas Teknik, Universitas Andalas \\ 1'asmuliardi@eng.unand.ac.id, ${ }^{2}$ ikhwan@eng.unand.ac.id*, ${ }^{3}$ ahmadsi@eng.unand.ac.id, ${ }^{4}$ mahiraf21@ gmail.com
}

\begin{abstract}
Technology has been growing rapidly to help humans living their everyday life. Human, as the user interacts through an interface called user interface (UI), and the experience that the users are having is called user experience (UX). UI and UX are inseparable as a good user interface will result in a better user experience. Portal Unand is a web-based app that has all academic information for students. An initial survey was conducted to find out student's thoughts on Portal Unand. Students have complaints towards Portal Unand due to its unresponsiveness, old-fashioned design, important features weren't highlighted, etc. Hence, it reduced user experience in using Portal Unand. In this study, the redesign was done by using the design thinking. The study started from empathizing with the users until testing the prototype to the users by conducting usability testing. Usability testing was conducted by using Maze and System Usability Scale (SUS). The score of usability testing was 84 which fell into the high range. The SUS score was 83.33 which fell into grade A and acceptable category. As the new prototype managed to fulfill users' needs and met users' expectations, the prototype was usable and ready to be developed.
\end{abstract}

Keywords: design thinking, responsiveness, usability testing, user interface, user experience

\begin{abstract}
Abstrak
Teknologi telah berkembang sangat pesat guna membantu manusia dalam menjalani kehidupan sehari-hari. Manusia, sebagai pengguna berinteraksi melalui antarmuka yang disebut dengan user interface (UI), dan pengalaman yang dirasakan pengguna disebut dengan user experience (UX). UI dan UX tidak dapat dipisahkan karena user interface yang baik akan menghasilkan user experience yang baik. Portal Unand merupakan aplikasi berbasis web yang memiliki segala informasi akademik untuk mahasiswa. Survei awal dilakukan untuk mengetahui pendapat mahasiswa mengenai Portal Unand. Mahasiswa mempunyai beberapa keluhan terhadap Portal Unand yang disebabkan oleh web yang tidak responsive, desain yang kuno, fitur yang tidak ditonjolkan, dll. Oleh sebab itu, pengalaman pengguna dalam menggunakan Portal Unand tidak begitu memuaskan. Pada penelitian ini dilakukan perancangan ulang dengan menggunakan metode design thinking. Penelitian dimulai dengan berempati dengan pengguna hingga menguji prototipe kepada pengguna dengan melakukan usability testing. Setelah prototipe selesai, usability testing dilakukan dengan menggunakan Maze dan System Usability Scale (SUS). Skor dari usability testing adalah 84 dimana skor tersebut terdapat dalam rentang tinggi. Skor SUS adalah 83,33 yang masuk kedalam kategori A dan dapat diterima. Hasil dari penelitian ini adalah sebuah prototipe usulan yang memenuhi aspek usability, yaitu efektivitas, efisiensi dan kepuasan pengguna. Aspek efektivitas dan efisiensi dilihat berdasarkan skor Maze yaitu 84, dan aspek kepuasan pengguna dilihat berdasarkan skor SUS yaitu 83,33.
\end{abstract}

Kata kunci: design thinking, responsif, usability testing, user interface, user experience

\section{Pendahuluan}

Perkembangan teknologi sangat pesat pada zaman sekarang ini. Hampir semua orang menggunakan teknologi, seperti smartphone, komputer, dll. Manusia, sebagai pengguna, berinteraksi dengan teknologi melalui antarmuka. Oleh sebab itu, terciptalah interaksi manusia-komputer atau human-computer interaction.
Interaksi manusia-komputer merupakan kajian studi yang berfokus kepada interaksi yang terjadi antara manusia dan komputer [1]. Interaksi terjadi melalui perantara yang disebut antarmuka atau user interface (UI) dan pengalaman yang dirasakan pengguna saat berinteraksi disebut user experience (UX). User interface (UI) merupakan sebuah tampilan atau 
antarmuka yang digunakan oleh pengguna untuk Berikut adalah perbandingan tampilan halaman login berinteraksi dengan sistem melalui perintah atau Teknik SIX ITB.

[2]. User experience (UX) menjelaskan perasaan pengguna sebelum, saat, dan setelah berinteraksi dengan sistem [3]. UI dan UX tidak dapat dipisahkan karena kedua hal tersebut saling melengkapi satu sama lain. UX didapatkan melalui UI. UI yang responsif akan menghasilkan UX yang baik. Desain responsif adalah teknik yang memungkinkan website untuk dapat mengubah tampilannya sehingga menyesuaikan terhadap berbagai macam resolusi layar. Penelitian menyatakan bahwa pengguna lebih sering menyelesaikan tugasnya dengan menggunakan smartphone daripada laptop [4]. Penyelesaian tugas yang lebih baik akan menghasilkan kepuasan bagi pengguna.

Portal Unand merupakan tampilan dari Sistem Informasi Akademik Universitas Andalas. Portal Unand merupakan aplikasi berbasis web yang memiliki informasi akademik dan menghubungkan mahasiswa dengan staf akademik. Aplikasi berbasis web dapat diakses di smartphone dan desktop dengan menggunakan web browser. Penelitian terdahulu menunjukkan bahwa 96\% mahasiswa Indonesia mempunyai smartphone [5]. Survei pendahuluan dilakukan untuk mengetahui pendapat mahasiswa Universitas Andalas terhadap Portal Unand. Survei disebarkan menggunakan google form dan hasilnya adalah 85,9\% mahasiswa Universitas Andalas menggunakan ponsel dalam kesehariannya.

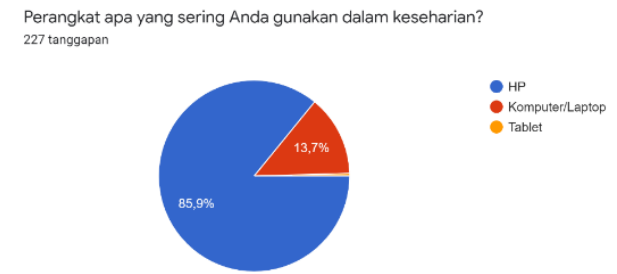

Gambar 1. Perangkat Mahasiswa

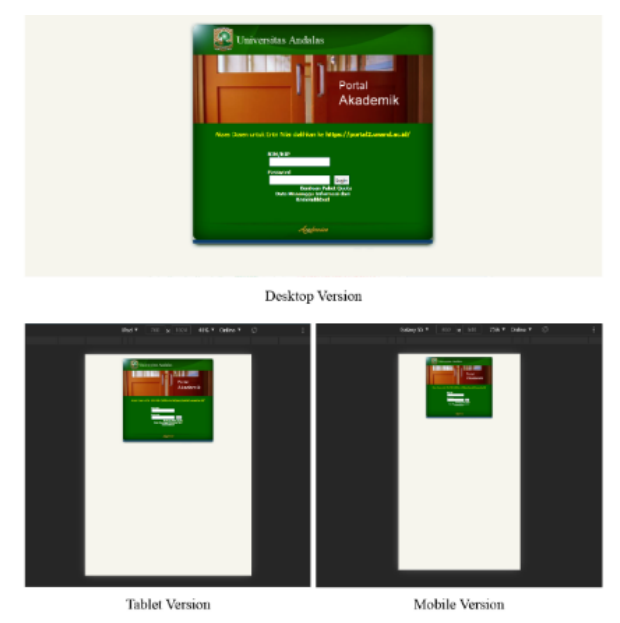

Gambar 2. Perbandingan Tampilan Portal Unand
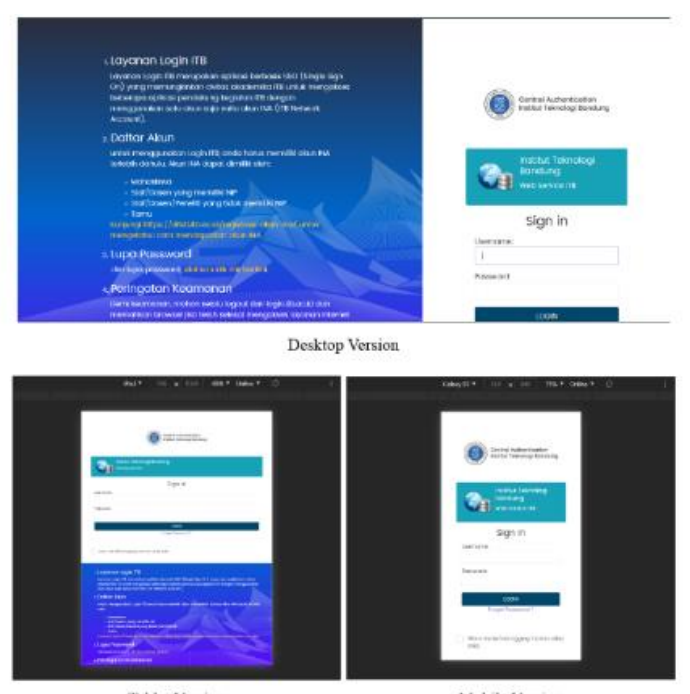

Mobile Version

Gambar 3. Perbandingan Tampilan SIX ITB

Gambar 3 memperlihatkan contoh website yang responsif. Terlihat bahwa desain tersebut menyesuaikan terhadap resolusi layar berbeda sehingga memudahkan pengguna untuk mengakses website dari segala jenis perangkat. Berdasarkan perbandingan ini, dapat disimpulkan bahwa website Portal Unand tidak responsif terhadap resolusi layar perangkat saat ini. Pada survei pendahuluan, mahasiswa dimintai pendapat mengenai keluhan terkait Portal Unand.

Gambar 1 memperlihatkan fakta bahwa versi mobile dar sebuah website lebih sering diakses daripada vers desktop. Namun, tampilan website Portal Unand tidak menyesuaikan kepada perangkat mobile dikarenakan masih menggunakan teknologi terdahulu. Oleh karena itu, Portal Unand dapat dikatakan tidak responsif. Desain yang responsif merupakan desain yang dapat menyesuaikan terhadap resolusi layar [6]. Sebuah website hendaknya dibuat responsif agar dapat memberikan pengalaman pengguna atau user experience yang baik. Terlihat pada Gambar 2 bahwa Portal Unand tidak responsif terhadap resolusi layar saat ini.

Terlihat pada Gambar 2 bahwa Portal Unand tidak menyesuaikan terhadap resolusi layar perangkat zaman sekarang. Salah satu contoh website yang responsif adalah SIX ITB atau Sistem Informasi Akademik ITB.

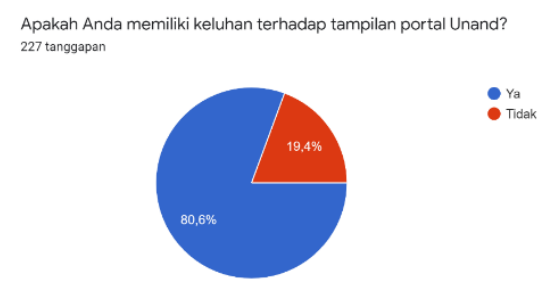

Gambar 4. Keluhan Mahasiswa Terhadap Portal Unand

DOI: https://doi.org/10.29207/resti.v5i6.3532

Lisensi: Creative Commons Attribution 4.0 International (CC BY 4.0) 
Menurut survei pendahuluan, $80,6 \%$ pengguna memiliki responsive, desain yang kuno, dan fitur utama yang tidak keluhan terhadap tampilan Portal Unand. Terdapat ditonjolkan. Oleh sebab itu, permasalahan ini $64,3 \%$ pengguna yang mengeluh karena harus zoom menghasilkan pengalaman pengguna atau user in/zoom out ketika menggunakan Portal Unand, 53,3\% experience yang kurang menyenangkan. Permasalahan pengguna menyatakan bahwa desain tidak menarik, tersebut menyalahi beberapa aturan dalam UX atau the 46,7\% pengguna mengeluhkan desain yang tidak UXlaws yaitu Postel's law dan Hick's law. responsif, $41,9 \%$ pengguna kesulitan menekan tombol, $35,7 \%$ menyatakan bahwa fitur utama tidak ditonjolkan, dan lainnya mengatakan bahwa informasi tidak diperbarui, terlalu banyak tulisan pada halaman awal, dan server yang tidak memadai. Permasalahan ini mengindikasi bahwa pengguna tidak mendapatkan user experience yang baik ketika menggunakan Portal Unand, terutama mengenai permasalahan website yang tidak responsif.

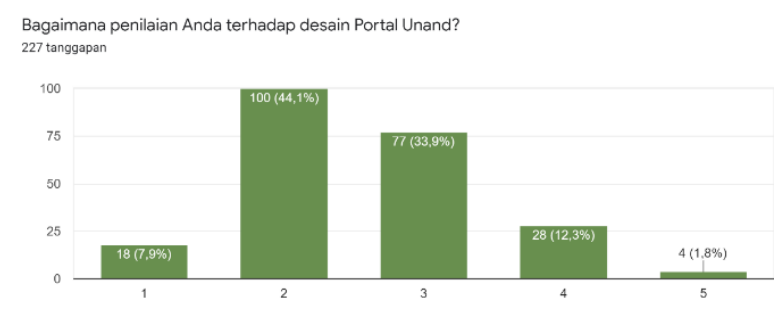

Gambar 5. Penilaian Mahasiswa Mengenai Tampilan Portal Unand

User experience sangat erat hubungannya dengan user interface. Mahasiswa dimintai pendapat mengenai desain Portal Unand dan 44,1\% mahasiswa memilih 2 dari 5, yaitu tidak menarik. Mahasiswa juga dimintai alasan memilih nomor 1 atau 2, dan hasilnya adalah $53,3 \%$ menyatakan bahwa desain tidak menarik karena kuno, 43,6\% mengatakan bahwa huruf terlalu kecil, $34,8 \%$ memilih karena tata letak yang tidak menarik, 0,4 mahasiswa mengatakan bahwa mereka harus memperbesar layar agar dapat melihat tulisan, dan lainnya tidak memilih 1 atau 2.

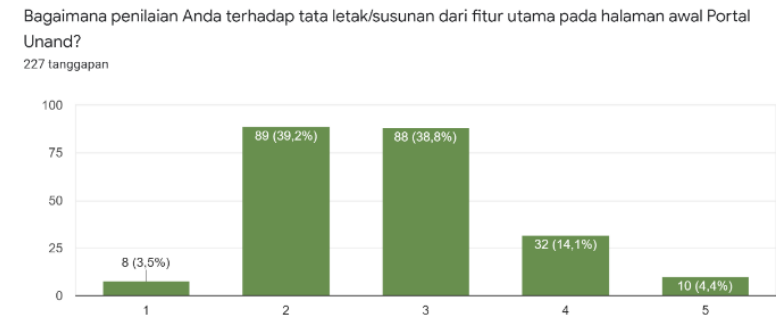

Gambar 6. Penilaian Mahasiswa Mengenai Tata Letak Portal Unand

Salah satu aspek yang penting dalam user interface adalah tata letak. Mahasiswa diminta untuk menilai tata letak Portal Unand dan 39,2\% memilih skala 2 dari 5, yaitu tidak menarik. Alasan dari pemilihan skala tersebut adalah 39,2\% mahasiswa menyatakan bahwa fitur utama tidak ditonjolkan dan 39,2\% menyatakan bahwa halaman awal terlalu ramai.

Berdasarkan survei pendahuluan, dapat dinyatakan bahwa Portal Unand memiliki website yang tidak

Postel's law, sebagai salah satu prinsip UX, menjelaskan bahwa pendekatan terhadap desain adalah mengantisipasi masalah dengan menyediakan antarmuka yang mudah diakses dan dapat diandalkan [7]. Kebanyakan pengguna Portal Unand menggunakan ponsel atau smartphone dalam keseharian. Layar ponsel relatif lebih kecil sehingga memiliki visibilitas yang rendah. Pengguna harus memperbesar layar agar dapat menggunakan Portal Unand dikarenakan desain yang tidak responsif. Desain yang tidak responsif mengakibatkan pengguna mengalami kesulitan untuk login atau menemukan fitur. Hal ini mengurangi kenyamanan pengguna dan menyalahi Postel's law. Oleh sebab itu, antarmuka pengguna yang responsif dibutuhkan agar dapat meningkatkan kenyamanan pengguna.

Adapun prinsip UX lainnya, yaitu Hick's law, mendeskripsikan perilaku manusia dalam mengambil keputusan. Banyaknya pilihan akan memakan lebih banyak waktu untuk mengambil keputusan [7]. Mahasiswa yang menggunakan Portal Unand bertujuan untuk mengecek KRS atau KHS mereka. Namun, halaman awal Portal Unand menyediakan informasi yang terlalu banyak dan tidak menonjolkan fitur utama. Perbandingan halaman awal Portal Unand dapat dilihat pada gambar 7.

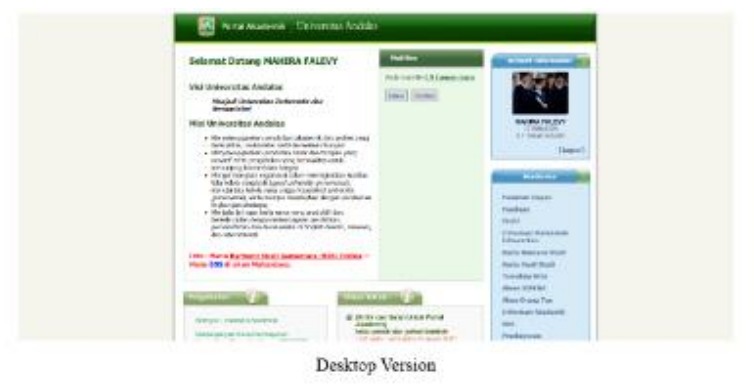

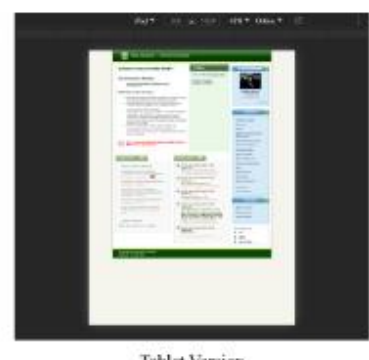

Tublet Version

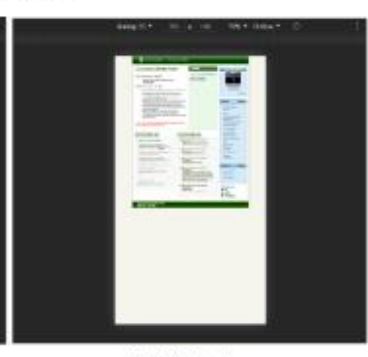

Mobile Versicu

Gambar 7. Perbandingan Halaman Awal Portal Unand
Gambar 7 memperlihatkan bahwa pengguna disajikan terhadap banyak informasi yang tidak relevan dengan tujuan mereka setelah mereka masuk ke Portal Unand. Menurut Hick's law, antarmuka yang memiliki tujuan

DOI: https://doi.org/10.29207/resti.v5i6.3532

Lisensi: Creative Commons Attribution 4.0 International (CC BY 4.0) 
yang tidak jelas atau sulit untuk diidentifikasi dan menghasilkan pengalaman pengguna yang kurang menyulitkan pengguna untuk menemukan informasi menyenangkan. Oleh karena itu, perumusan masalah yang dibutuhkan akan menambah beban kognitif pada pada penelitian ini adalah bagaimana cara meningkatkan pengguna [7]. Oleh karena itu, menyederhanakan user experience dengan melibatkan pengguna dalam tampilan membantu mengurangi beban mental pada proses perancangan ulang Portal Unand. Adapun tujuan pengguna dan akan menghasilkan user experience yang dari penelitian ini adalah untuk membuat usulan desain lebih baik.

Agar dapat meningkatkan pengalaman pengguna atau user experience bagi pengguna Portal Unand, dibutuhkan perancangan ulang atau redesign. Mahasiswa dimintai pendapat mengenai redesign Portal Unand dan $89,9 \%$ setuju bahwa Portal Unand butuh untuk didesain ulang.

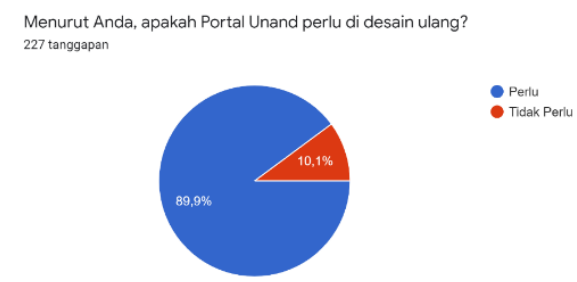

Gambar 8. Tanggapan Pengguna Terkait Redesign

Portal Unand yang dapat menyelesaikan permasahan pengguna, memenuhi kebutuhan pengguna, dan membantu pengguna untuk mencapai tujuannya.

\section{Metode Penelitian}

Penelitian terdiri dari beberapa tahapan yang dilakukan berdasarkan diagram alur metode penelitian. Gambar 9 diagram alur metode penelitian.

Berdasarkan gambar tersebut, penelitian dimulai dengan melakukan studi pendahuluan dan studi literatur, setelah itu permasalahan diidentifikasi dan diformulasi, kemudian memilih metode yaitu design thinking. Metode tersebut berfokus pada empati, yang berarti menempatkan diri di posisi pengguna dan mengobservasi pengguna secara detail [10]. Terdapat lima tahapan dalam metode design thinking, yaitu empathize, define, ideate, prototype, dan test [11].

Portal Unand yang didesain ulang dengan menggunakan design thinking yang berfokus kepada kebutuhan pengguna akan menghasilkan user experience yang Tahapan empathize bertujuan untuk memahami lebih baik. Design thinking merupakan metode yang pengguna agar dapat mengidentifikasi masalah. Hal berfokus terhadap pengguna. Metode tersebut tersebut dapat dilakukan dengan riset pengguna, seperti melibatkan pengguna dalam setiap prosesnya. melakukan wawancara atau observasi pengguna [12]. Keterlibatan pengguna akan menghasilkan desain yang Tahapan ini dilakukan untuk mengetahui pendapat memenuhi kebutuhan pengguna. Desain Portal Unand pengguna tentang Portal Unand. Metoda yang dilakukan yang diusulkan diharapkan dapat memenuhi kebutuhan adalah dengan menyebarkan kuesioner daring kepada pengguna, membantu pengguna dalam mencapai tujuan, mahasiswa Universitas Andalas. Pertanyaan yang dan menghadirkan user experience yang lebih baik.

Penelitian terdahulu oleh Rusanty, et. al (2019) membahas mengenai perancangan aplikasi mobile dengan menggunakan metode design thinking. Proses design thinking dilakukan dengan wawancara terhadap pengguna, membuat user persona, wireframe, dan highfidelity prototype. Prototype tersebut kemudian diujikan terhadap pengguna dengan melakukan usability testing yang dikombinasikan dengan system usability scale [8]. Penelitian lainnya oleh Vallendito (2020) membahas mengenai pemodelan user interface dan user experience dengan metode design thinking. Proses design thinking dimulai dengan fase emphatize dengan wawancara pengguna dan menyebarkan kuesioner, fase define dengan membuat user persona, user scenario, dan customer journey map, fase ideate dengan membuat user flow dan sitemap, fase prototype dengan membuat wireframe dan high-fidelity prototype, dan fase testing dengan melakukan usability testing yang dikombinasikan dengan usability test questionnaire [9].

Berdasarkan paparan, permasalahan yang dialami diajukan berkisar tentang data pengguna, preferensi perangkat yang digunakan, dan penilaian pengguna terhadap user interface dan user experience.

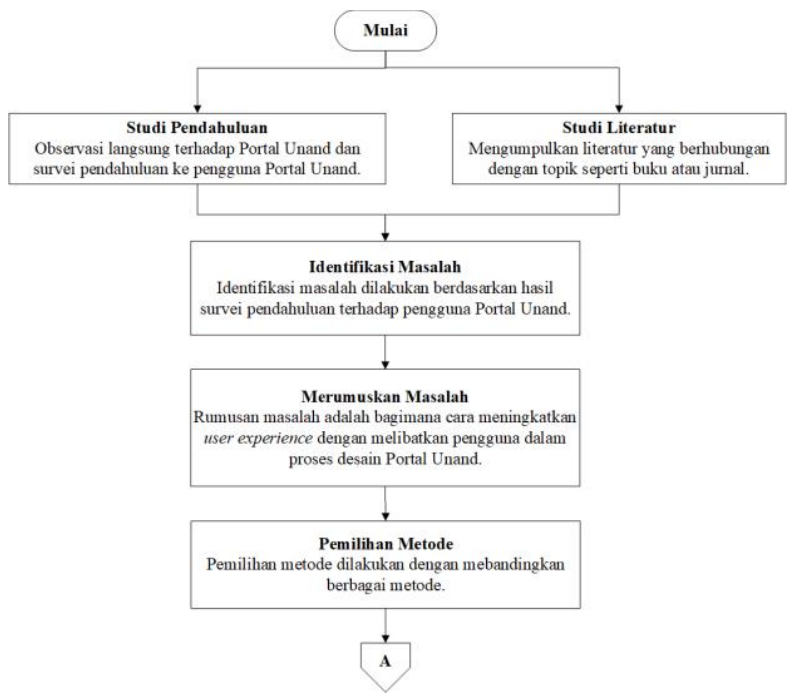

Gambar 9. Diagram Alur Metode Penelitian utama yang tidak ditonjolkan. Permasalahan ini 


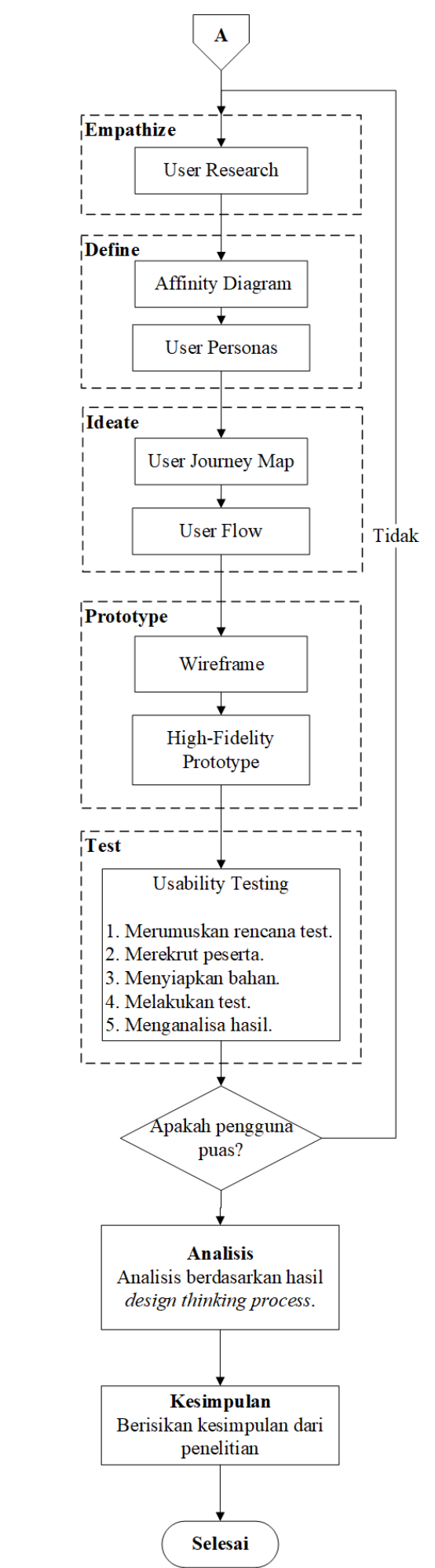

Gambar 10. Diagram Alur Metode Penelitian (Lanjutan)
Kemudian, target pengguna ditentukan dengan membuat user persona yang merupakan model yang merepresentasikan pengguna dan cerita pengguna [14].

Tahapan selanjutnya adalah ideate, yang bertujuan untuk menciptakan solusi atas permasalahan pengguna [13]. Solusi dapat diideasi dengan menggunakan user journey map dan user flow. User journey map merupakan alat yang memvisualisasikan perjalanan pengguna dalam menggunakan suatu produk untuk mencapai suatu tujuan [7]. User flow mendeskripsikan alur bagaimana pengguna menggunakan suatu produk [15].

Tahapan selanjutnya adalah prototype, yang bertujuan untuk merealisasikan solusi. Prototype merupakan demonstrasi suatu produk yang interaktif sehingga dapat digunakan untuk menentukan usabilitas dari suatu produk [16]. Terdapat tiga jenis prototype, yaitu lowfidelity prototype atau paper mock-up, medium-fidelity prototype atau wireframe, dan high-fidelity prototype [17].

Tahapan terakhir adalah test atau pengujian prototype. Pengujian dilakukan langsung terhadap pengguna untuk mendapatkan feedback dan pemahaman yang lebih dalam terhadap pengguna [13]. Pada tahapan test, hal terpenting adalah usabilitas dari suatu produk. Usabilitas adalah seberapa jauh sebuah produk dapat digunakan oleh pengguna berdasarkan efektivitas, efisiensi, dan kepuasan dalam konteks usabilitas untuk mencapai tujuan tertentu [18]. Pengujian dilakukan dengan usability testing yaitu suatu cara untuk menguji produk dimana sejumlah kegiatan representatif atau representative task dicobakan oleh pengguna yang bertujuan untuk meningkatkan kualitas antarmuka berdasarkan temuan [19]. Usability testing dilakukan dengan Maze. Tahapan dalam usability testing adalah membuat rencana testing, merekrut partisipan, menyusun bahan, melakukan usability testing, dan menganalisa hasil usability testing.

Setelah melakukan tahapan design thinking, langkah selanjutnya adalah menganalisis hasil penelitian dan menarik kesimpulan.

\section{Hasil dan Pembahasan}

Penelitian dilakukan dengan menggunakan metode design thinking yang terdiri dari lima tahapan. Tahapan empathize, define, dan ideate berfokus pada perancangan user experience. Tahapan prototype berfokus pada perancangan user interface, sedangkan tahapan test berfokus pada usability testing.

Tahapan define bertujuan untuk menentukan permasalahan yang dialami dengan membuat problem statement [13]. Pada tahapan define, penentuan masalah dapat dilakukan dengan membuat affinity diagram. Affinity diagram merupakan diagram yang mengelompokkan data kualitatif untuk mendapatkan kesimpulan atau menentukan permasalahan [3].

\subsection{User Experience}

Perancangan user experience dilakukan pada tahapan empathize, define, dan ideate. Pada tahapan perancangan user experience dilakukan survei terhadap pengguna untuk mengetahui permasalahan. Setelah itu, 
permasalahan dikelompokkan untuk menentukan solusi. kebutuhan. Berdasarkan hasil survei, didapatkan dua Kemudian, dilakukan proses ideasi untuk menentukan user persona.

solusi nyata yang dapat dilakukan untuk meningkatkan pengalaman pengguna.

Perancangan user experience menghasilkan output berupa permasalahan pengguna, user journey, dan user flow. Berikut adalah rincian mengenai tahapan yang dilakukan.

\subsubsection{Empathize}

Empati merupakan tahap pertama yang dilakukan untuk mengenal pengguna dari Portal Unand. Dimulai dari tanggapan pengguna terhadap Portal Unand, permasalahan yang dialami oleh pengguna, dan rekomendasi pengguna terhadap Portal Unand. Tahapan empati dilakukan dengan menyebarkan kuesioner kepada mahasiswa Universitas Andalas menggunakan Google Form. Hasil yang didapatkan adalah preferensi perangkat yang digunakan mahasiswa yaitu $86,4 \%$ menggunakan smartphone, lima fitur yang paling sering digunakan yaitu KRS, KHS, Transkrip, Pembayaran, dan Mata Kuliah, dan tanggapan mahasiswa terkait Portal Unand. 79\% mahasiswa memiliki komplain terhadap tampilan Portal Unand, dimana 44,1\% mahasiswa memilih skor 2 dari 5 sebagai penilaian mereka terhadap tampilan Portal Unand, 39,2\% mahasiswa memilih skor 2 dari 5 sebagai penilaian mereka terhadap susunan menu di halaman utama Portal Unand, dan 88,9\% mahasiswa menyatakan bahwa Portal Unand perlu dirancang ulang (redesign).

\subsubsection{Define}

Setelah berempati dengan pengguna, tahapan selanjutnya adalah menentukan masalah dan target pengguna. Tahapan ini dilakukan dengan membuat affinity diagram dan user persona. Affinity diagram digunakan untuk mengelompokkan informasi yang sejenis hingga mendapat kesimpulan.

Informasi yang didapatkan berupa permasalahan terkait antarmuka, fitur utama yang tidak ditonjolkan, informasi yang tidak diperbarui, serta kebutuhan, keinginan, dan hal yang membuat pengguna tidak nyaman. Oleh sebab itu, dapat disimpulkan bahwa pengguna membutuhkan tampilan yang baru untuk Portal Unand agar dapat meningkatkan pengalaman pengguna dalam menggunakan Portal Unand. Selain itu, dapat disimpulkan juga bahwa pengguna tidak mempunyai pengalaman atau user experience yang menyenangkan selama menggunakan Portal Unand. Hasil akhir dari pengelompokan informasi tersebut adalah didapatkannya solusi yaitu untuk memperbarui tampilan Portal Unand.

User persona merupakan model yang merepresentasikan pengguna Portal Unand. User persona berisikan informasi mengenai pengguna, seperti biodata dan demografi, prilaku, frustrasi, tujuan, dan
Tabel 1. User Persona 1

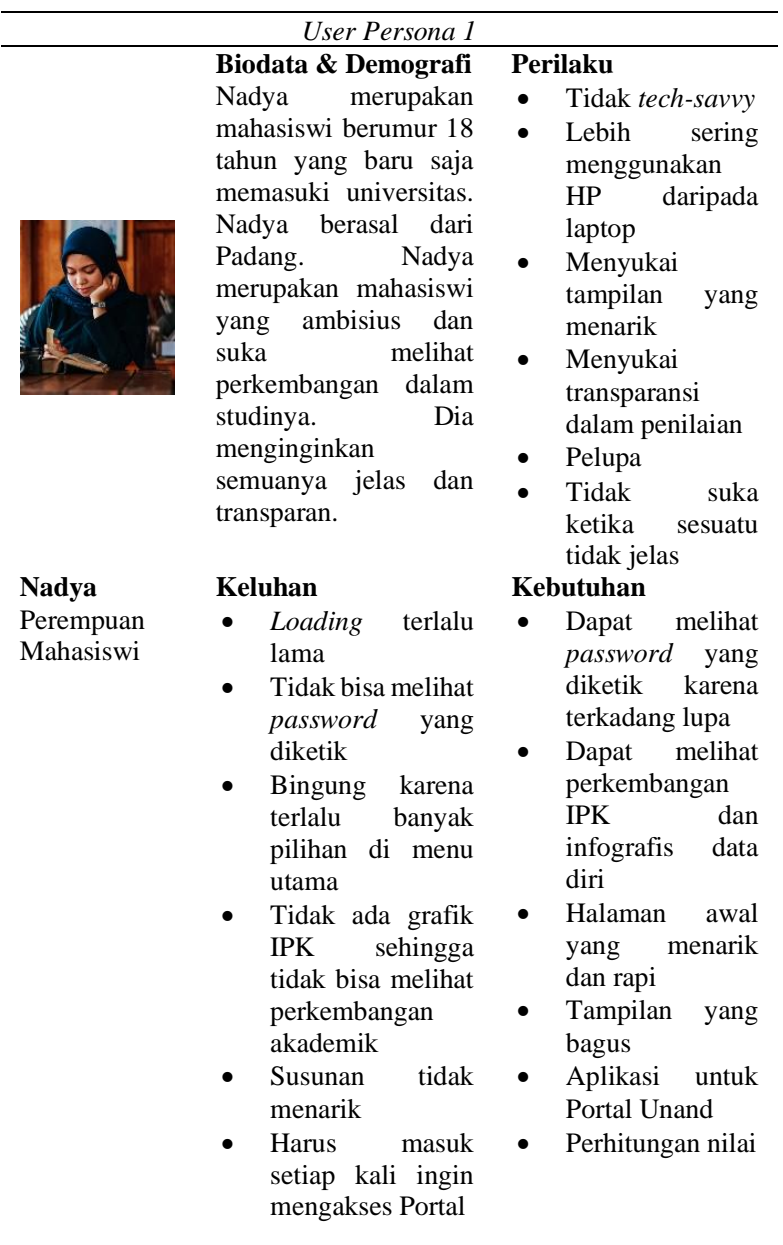

Persona pertama merupakan representasi dari mahasiswa yang baru di dunia perkuliahan. Dia memiliki ambisi untuk studinya dan ingin melihat perkembangan studinya.

Persona kedua merepresentasikan mahasiswa yang sudah lama berkuliah. Mahasiswa ini senang mempelajari hal baru dan membutuhkan informasi bermanfaat. Sebagai mahasiswa yang sudah lama berkuliah, ia memiliki lebih banyak keluhan terkait Portal Unand.

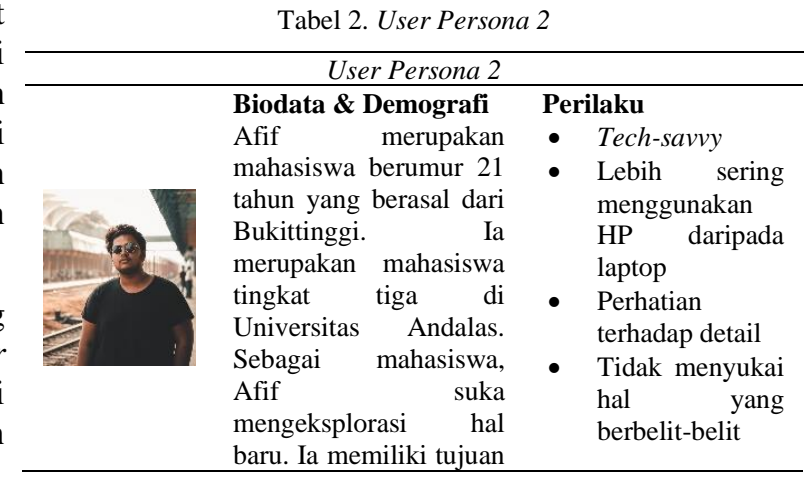




\begin{tabular}{|c|c|c|}
\hline $\begin{array}{l}\text { Afif } \\
\text { Laki-laki } \\
\text { Mahasiswa }\end{array}$ & 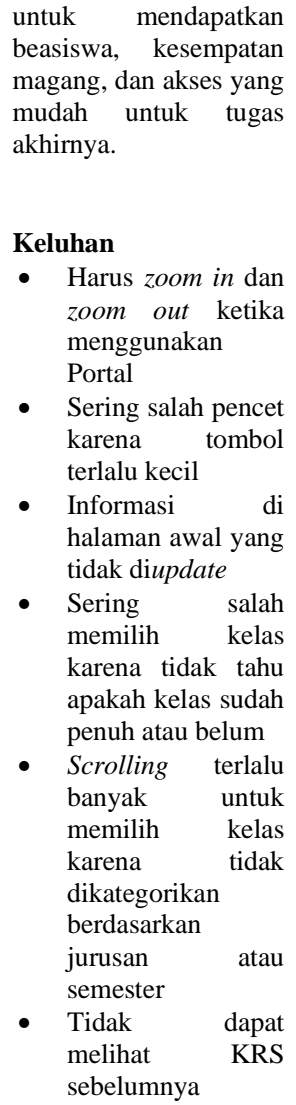 & 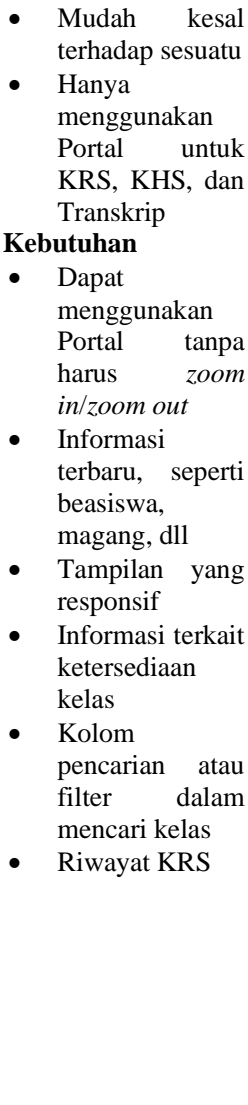 \\
\hline
\end{tabular}

\subsubsection{Ideate}

Proses ideasi dilakukan dengan membuat user journey map dan user flow. User journey map berfungsi untuk memvisualisasikan perjalanan pengguna dalam mencapai tujuannya. User flow mendeskripsikan alur pengguna dalam mencapai tujuannya serta menjelaskan alur dari aplikasi tersebut.

Dalam pembuatan user journey map, langkah yang harus dilalui pengguna didefinisikan dan setiap langkah tersebut dianalisa. Aktivitas yang dilakukan pada setiap langkah ditentukan, painpoints atau titik yang mengganggu bagi pengguna ditentukan, kemudian solusi untuk mengatasi permasalah pengguna berdasarkan langkah ditentukan.

Terdapat dua jouney map, user journey map pertama menggambarkan pengguna yang bertujuan untuk mengisi KRS. Terdapat empat langkah utama untuk mencapai tujuan pengguna, yaitu masuk Portal Unand, melihat halaman utama, mengisi form KRS, dan mencetak KRS.

Selanjutnya dibuat user journey map untuk pengguna yang bertujuan untuk mengecek KHS dan Transkripnya. Terdapat empat langkah utama untuk mencapai tujuan pengguna, yaitu masuk Portal Unand, melihat halaman utama, melihat KHS, dan mencetak KHS.
Pada pembuatan user journey map, terdapat peluang yang berisikan solusi atas permasalahan yang dirasakan pengguna. Solusi tersebut kemudian diimplementasikan pada tahapan selanjutnya, yaitu merancang user flow dan membuat prototype.

User flow dirancang sedemikian rupa untuk menggambarkan alur dari Portal Unand, dimulai dari pengguna memasuki Portal Unand hingga mencapai tujuan pengguna yaitu mencetak KRS, KHS, atau transkrip. Adapun pembaharuan yang ditambahkan pada Portal Unand adalah alur untuk penggantian kata sandi apabila pengguna lupa akan kata sandinya. Alur ini ditambahkan karena pengguna terkadang lupa akan kadang sandinya dan sulit untuk mengurus perubahan kata sandi jika tidak bisa dilakukan di aplikasi. Oleh sebab itu ditambahkan alur untuk penggantian kata sandi.

\subsection{User Interface}

Tahapan selanjutnya adalah perancangan user interface dengan membuat prototype. Prototype yang dibuat terdiri atas wireframe dan high-fidelity prototype. Wireframe merupakan sketsa dari aplikasi yang menampilkan tata letak dari fitur yang dibutuhkan. Berikut adalah wireframe dari Portal Unand.

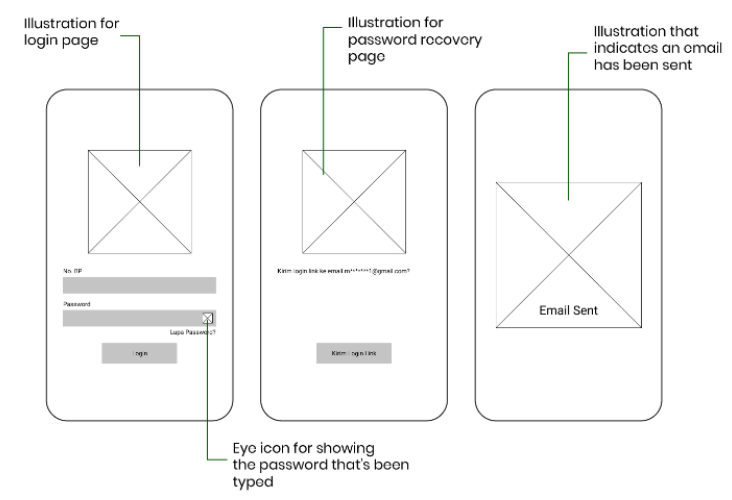

Gambar 11. Wireframe Alur Pemulihan Sandi

Gambar 11 memperlihatkan wireframe untuk tampilan yang dibutuhkan dalam alur pemulihan kata sandi. Terdapat tiga tampilan, yaitu tampilan masuk, tampilan konfirmasi pengiriman email, dan tampilan konfirmasi bahwa email telah dikirim. Pada tampilan tersebut dijelaskan tata letak dari fitur yang dibutuhkan.

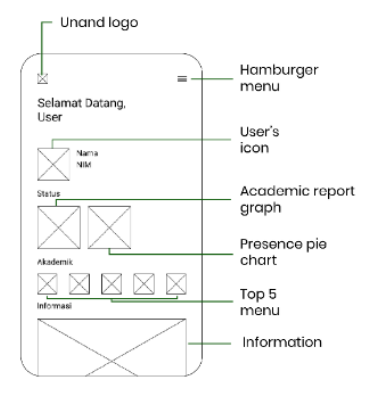

Gambar 12. Wireframe Halaman Awal

DOI: https://doi.org/10.29207/resti.v5i6.3532

Lisensi: Creative Commons Attribution 4.0 International (CC BY 4.0) 
Gambar 12 memperlihatkan wireframe untuk tampilan tertentu dengan menggunakan filter. Skor yang halaman awal. Pada halaman awal terdapat informasi dihasilkan adalah 84 dan termasuk kedalam rentang yang dibutuhkan oleh pengguna. Tata letak tersebut tinggi.

disusun berdasarkan hasil riset dan proses ideasi yang dilakukan saat perancangan user experience.
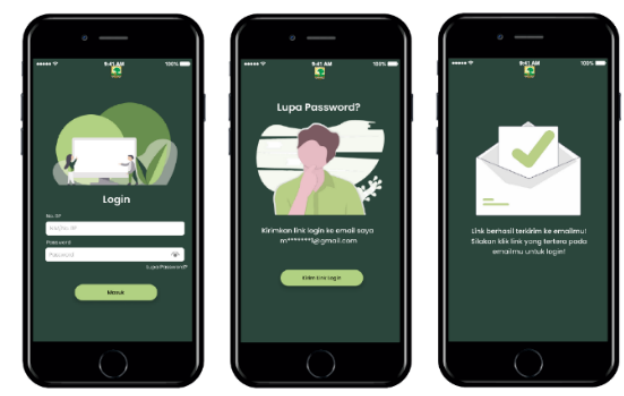

Gambar 13. User Interface Alur Pemulihan Sandi
Setelah melakukan Maze Usability Testing, partisipan diminta untuk mengisi kuesioner System Usability Scale untuk mengetahui tingkat kepuasan pengguna. Skor yang didapat adalah 83,33 dimana skor tersebut termasuk kedalam grade $A$ dan kategori dapat diterima.

Berdasarkan hasil usability testing, terlihat bahwa prototype yang dirancang dapat digunakan dengan baik atau usable. Prototype yang dirancang juga memenuhi tiga elemen utama dalam usability, yaitu efficiency, effectiveness, dan satisfaction. Efficiency dan effectiveness dapat dilihat dari skor Maze yang termasuk kedalam rentang tinggi. Satisfaction dapat dilihat dari skor System Usability Scale yang termasuk kedalam

Gambar 13 memperlihatkan high-fidelity prototype dari kategori dapat diterima. Oleh sebab itu, prototype usulan tampilan alur pemulihan sandi. High-fidelity prototype dapat digunakan oleh pengguna dan siap untuk didesain berdasarkan sketsa yang dibuat.
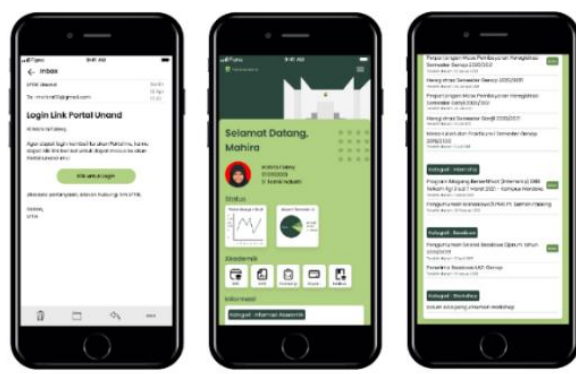

Gambar 14. User Interface Halaman Awal

Gambar 14 memperlihatkan high-fidelity prototype dari tampilan halaman email dan halaman awal. Warna utama yang digunakan pada Portal Unand adalah hijau dan putih. Warna hijau digunakan karena melambangkan perkembangan dan kestabilan, selain itu warna hijau juga merupakan warna utama dari Universitas Andalas. Warna putih melambangkan kesederhanaa, kebersihan, dan kebaikan.

\subsection{Usability Testing}

High-fidelity prototype dibuat interaktif agar dapat diuji langsung oleh pengguna melalui usability testing. Usability testing dilakukan dengan menggunakan Maze. Pengujian dilakukan dengan model independent groups design atau between subjects design, dimana tiap bagian dari prototype diujikan kepada pengguna yang berbeda dikarenakan pengujian yang dilakukan cukup lama dan ada kemungkinan untuk pengguna menjadi lelah.

Pengujian pertama berfokus untuk menguji alur pemulihan sandi, fitur KHS, dan fitur Transkrip. Skor yang dihasilkan adalah 84 dan termasuk kedalam rentang tinggi.

Pengujian kedua berfokus untuk menguji alur pengisian KRS, dimana pengguna diminta untuk memilih kelas dikembangkan.

\subsection{Peningkatan User Experience}

Peningkatan user experience didasarkan kepada hukum UX atau the UX laws oleh Yablonski. Hukum pertama adalah Jakob's law yang membahas tentang familiarity, dimana desain yang akrab dengan pengguna akan meningkatkan user experience. Kedua adalah Fitt's law yang membahas tentang antarmuka. Antarmuka atau interface yang baik hendaknya memuat informasi yang dibutuhkan pengguna. Ketiga adalah Hick's law yang membahas tentang waktu yang dibutuhkan pengguna untuk membuat keputusan. Semakin singkat waktu yang yang jelas dan mudah dimengerti. Keempat adalah Miller's law yang membahas tentang memori manusia, dimana manusia memiliki memori terbatas. Kelima adalah Postel's law yang membahas tentang desain responsif. Desain yang baik adalah desain yang dapat menyesuaikan ke setiap perangkat pengguna. Keenam adalah Peak-End rule yang membahas tentang momen terakhir pengguna dalam suatu perjalanan. Ketujuh adalah Aesthetic-Usability effect dimana desain yang menarik akan memberikan persepsi bahwa desain tersebut mudah digunakan. Kedelapan adalah von Restorrf effect yang membahas tentang kontras atau perbedaan. Kesembilan adalah Tesler's law yang membahas tentang kompleksitas. Terakhir adalah Doherty Threshold yang membahas tentang performa dan visual engagement.

Proses redesign dilakukan dengan mengikuti metode design thinking dimana metode tersebut berfokus kepada pengguna atau user-centric. Oleh sebab itu, perbaikan yang dilakukan bertujuan untuk meningkatkan pengalaman pengguna atau user experience.

Desain yang diusulkan dirancang untuk menyesuaikan terhadap perangkat yang sering digunakan pengguna, dihabiskan, maka desain yang dibuat memiliki makna 
yaitu smartphone. Informasi yang ditonjolkan pada itu, menu fitur yang ditonjolkan adalah fitur yang paling halaman awal merupakan informasi yang dibutuhkan sering digunakan pengguna. Fitur lainnya oleh pengguna, seperti fitur utama yang sering disembunyikan pada hamburger menu untuk digunakan, informasi akademik yang dilengkapi label, menghindari halaman yang terlalu ramai. Kemudian, dan grafik akademik mahasiswa. Grafik yang disediakan profil pengguna serta grafik akademik juga membantu pengguna untuk melihat perkembangan ditambahkan.

studinya, sehingga menimbulkan visual engagement bagi pengguna. Tata letak yang diusulkan pun dirancang lebih sederhana agar pengguna tidak diberatkan dengan informasi yang berlebihan. Oleh karena itu, perbaikan yang dilakukan telah didasarkan terhadap the UX laws sehingga dapat meningkatkan user experience.

\subsection{Perbaikan User Interface}

Perbaikan yang dilakukan terhadap antarmuka pengguna atau user interface Portal Unand dapat dilihat pada gambar 15.

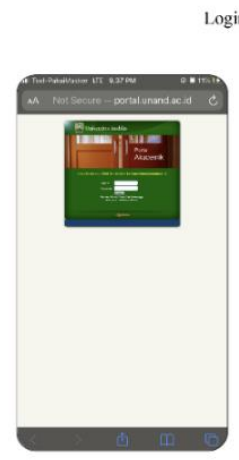

Current Portal Unand

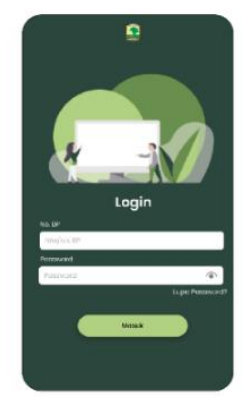

New Prototype

Gambar 15. Perbandingan Halaman Login

Gambar 15 memperlihatkan perbaikan yang dilakukan terhadap halaman login. Terlihat bahwa desain yang diusulkan menyesuaikan dengan perangkat mobile yang sering digunakan pengguna. Selain itu terdapat icon mata yang berfungsi untuk melihat password yang telah diketik. Selain itu, pengguna dapat menekan button link 'Lupa Password?' jika pengguna lupa akan kata sandinya. Kemudian, tombol login diletakkan di bagian bawah agar lebih mudah dijangkau bagi pengguna.

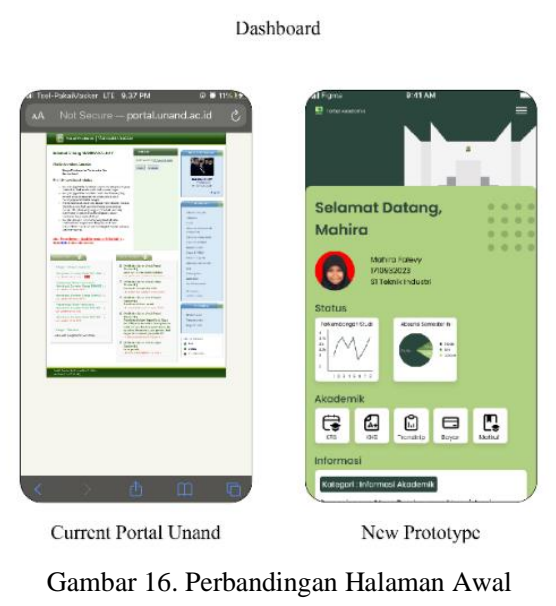

Halaman utama Portal Unand yang diusulkan dirancang untuk menyesuaikan terhadap tampilan mobile. Selain

\section{Kesimpulan}

Berdasarkan hasil penelitian, dapat disimpulkan bahwa desain yang diusulkan dapat menyelesaikan permasalahan pengguna, memenuhi kebutuhan pengguna, dan membantu pengguna untuk mencapai tujuannya. Desain usulan dibuat dengan mengikuti metode design thinking, dimulai dari empathize, define, ideate, prototype, dan test. Desain usulan dapat digunakan dengan mudah atau usable berdasarkan tiga kriteria utama dalam usability, yaitu effectiveness, efficiency, dan satisfaction. Aspek effectiveness dan efficiency diukur dengan menggunakan Maze yang menghasilkan skor 84 dan masuk ke dalam rentang tinggi. Aspek satisfaction diukur dengan menggunakan System Usability Scale dengan skor 83,33 yang termasuk kedalam grade $A$ dan kategori dapat diterima. Oleh sebab itu, desain usulan dapat digunakan dan siap dikembangkan.

\section{Daftar Rujukan}

[1] G. Fischer, "User Modeling in Human-Computer Interaction," User Modeling and User-Adapted Interaction, vol. 11, no. 1-2, pp. 65-86, 2001.

[2] H. Joo, "A Study on Understanding of UI and UX, and Understanding of Design According to User Interface Change," International Journal of Applied Engineering Research, pp. 9931-9935, 2017.

[3] R. Hartson and P. Pyla, The UX Book: Agile UX Design for a Quality User Experience, 2nd ed., Cambridge: Morgan Kaufmann, 2019.

[4] A. Hussain and E. O. Mkpojiogu, "THE EFFECT OF RESPONSIVE WEB DESIGN ON THE USER EXPERIENCE WITH LAPTOP AND SMARTPHONE DEVICES," Jurnal Teknologi (Sciences \& Engineering), pp. 41-47, 2015.

[5] A. R. Pratama, "Exploring Personal Computing Devices Ownership Among University Students in Indonesia," in Int. Conf. on Social Implications of Computers in Developing Countries, 2017.

[6] J. Marsh, UX for Beginners, 1st ed., Canada: O'Reilly Media Inc., 2016.

[7] J. Yablonski, Laws of UX: Using Psychology to Design Better Products \& Services, 1st ed., Sebastopol: O'Reilly Media, Inc., 2020.

[8] D. A. Rusanty, H. Tolle and L. Fanani, "Perancangan User Experience Aplikasi Mobile Lelenesia (Marketplace Penjualan Lele) Menggunakan Metode Design Thinking," Jurnal Pengembangan Teknologi Informasi dan Ilmu Komputer, vol. 3, no. 11, pp. 10484-10493, 2019.

[9] B. Vallendito, "Pemodelan User Interface dan User Experience Menggunakan Design Thinking," UIN Maulana Malik Ibrahim, Malang, 2020.

DOI: https://doi.org/10.29207/resti.v5i6.3532

Lisensi: Creative Commons Attribution 4.0 International (CC BY 4.0) 
[10] C. Mueller-Roterberg, Handbook of Design Thinking: Tips \& Tools for how to design thinking, Independently Published, 2018.

[11] M. L. Lazuardi and I. Sukoco, "Design Thinking David Kelley \& Tim Brown: Otak Dibalik Penciptaan Aplikasi Gojek," Organum: Jurnal Saintifik Manajemen dan Akuntansi, vol. 02, no. 1, pp. 1-11, 2019.

[12] A. Cooper, R. Reimann, D. Cronin and C. Noessel, About Face: The Essentials of Interaction Design, 4th ed., Indianapolis: John Wiley \& Sons, Inc., 2014.

[13] H. Platner, An Introduction to Design Thinking Process Guide, Stanford: Institute of Design at Stanford, 2010.

[14] L. Maioli, Fixing Bad UX Designs, 1st ed., Birmingham: Packt Publishing Ltd., 2018.

[15] B. Still and K. Crane, Fundamentals of User-Centered Design: A Practical Approach, New York: CRC Press, 2017.
[16] H. Sharp, J. Preece and Y. Rogers, Interaction Design: Beyond Human-Computer Interaction, Fifth Edition, 5th ed., Indianapolis: John Wiley \& Sons, 2019.

[17] B. Shneiderman, C. Plaisant, M. Cohen, S. Jacobs and N. D. N. Elmqvist, Designing the User Interface: Strategies for Effective Human-Computer Interaction, 6th ed., Harlow: Pearson Education, 2018.

[18] V. P. Sabandar and H. B. Santoso, "Evaluasi Aplikasi Media Pembelajaran Statistika Dasar Menggunakan Metode Usability Testing," TEKNIKA, vol. 7, no. 1, pp. 50-50, 2018.

[19] J. Lazar, J. H. Feng and H. Hochheiser, Research Methods in Human-Computer Interaction 2nd Edition, 2nd ed., Cambridge: Morgan Kaufmann, 2017. 